\title{
LE MESURIER'S OPERATION FOR HARE LIP*
}

\author{
BY \\ A. OBERNIEDERMAYR \\ From the Children's Hospital of the University of Munich
}

This is a report on hare lip operations performed by the method of le Mesurier (1949). Since 1955 we have done 238 operations on hare lips in the Children's Hospital in Munich. In 98 cases there were unilateral complete hare lips, in 27 cases bilateral complete hare lips. I shall discuss only the primary plastics and not the corrections which are often necessary, and I shall not mention the problem of cleft palate in spite of its connexions with hare lip.

We began in 1957 to operate on total palatoschisis in two stages. In the first operation at the end of the second year we close the soft palate, and the residual cleft is closed before the child starts to go to school. In the meantime we try to diminish the extent of the residual cleft by using a so-called stimulation plate, a method which is described by Schweckendiek (1955), McNeil (1956), and Derichsweiler (1958), but our experience with the stimulation plate is as yet insufficient to form any judgment.

In total unilateral hare lip we have to span the fissure not only in the frontal but also in the sagittal plane. There is no difficulty in closing the gap in the frontal plane, even if it is a very large one, but it is sometimes difficult to close the gap in the sagittal plane. As the two edges of the cleft are in different planes there results an oblique position of the nostril and the columella and a flattening of the wing of the nose at the side of the gap.

There are two problems in hare lip operations, the lip and the nostril. I think we should try at the first operation to undertake the corrections as far as possible, but the plastics of the nostril must not complicate and prolong the operation too long. I therefore postpone the plastics of the tip of the nose and the columella until later, if such correction is necessary at all. It is known that the likelihood of spontaneous correction is much greater in early childhood than later on.

Fig. 1 shows the original method of le Mesurier. At the outermost left side of the picture the final

\footnotetext{
* A paper read at a meeting of the British Association of Paediatric Surgeons held in Liverpool in June, 1959.
}

point of the medial incision and the centre of the upper lip do not coincide, but lie a few millimetres nearer to the cleft. The cause for this asymmetry following le Mesurier's operation is the difference in height of the lip on the normal side and the abnormal side. This causes a slight displacement of Cupid's bow towards the side of the cleft except in those rare cases where Cupid's bow is situated on the medial side of the gap.

Fig. 2 shows the incisions in total hare lip. The plastics of the base of the nose we do by the method of Axhausen (1936), using the mobilized flaps of the mucous membrane. We make a transverse incision at the base of the inferior nasal concha to put the lateral part of the cleft forward in the sagittal plane (Fig. 3). The starting points of the incisions we place a little in front of the nostril to have as much material as possible for the base of the nose. To ensure that the vertex of Cupid's bow is in the middle of the lip, the foot point of the medial incision is placed in the calculated middle of the demarcation line of the red border, even if the length of this medial incision is longer than normal, i.e. more than $8 \mathrm{~mm}$. If a good cosmetic result is risked by this procedure we can do a longitudinal correction by excision of a triangle. On the lateral part of the cleft the length of the incision is $8 \mathrm{~mm}$. It is very important that the incisions which form the later flap are exactly half as long as this longitudinal incision and exactly as long as the cross section on the longitudinal medial incision. The angle between the longitudinal and transverse incisions should be $90^{\circ}$. If a longitudinal correction on the lateral side of the cleft is necessary, this can be done by taking off a wedge at the insertion of the nose wing. With regard to the plastics of the wing of the nose, we do not undertake a dissection of both layers (mucous membrane and skin). If a dissection of the cartilages is necessary for a correction of the tip of the nose, for instance, it is very difficult if there has been any lesion of the cartilage in early childhood. The first correction of the sinking in of the side of the nose we do by a Z-plastic. Figs. 4 and 5 show the result of operation. 

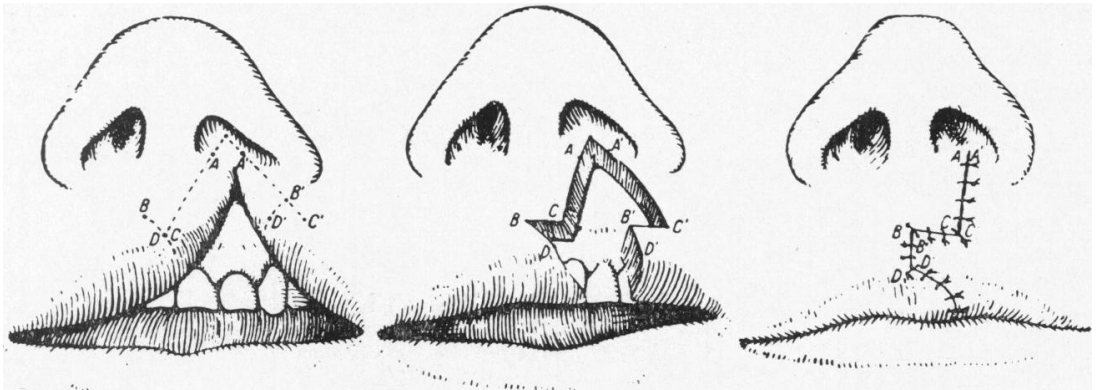

Fig. 1.-Original in Chirurgische Operationslehre B. Breitner, Printed in Austria, Copyright by Urban and Schwarzenberg-Wien. Vol. I, Fig. 4 d-e, p. 11.

In operations for total bilateral cheilognathouranoschisis, the greatest problem is the prominence of the premaxilla. Browne (1932) has pointed out that we must put the premaxilla in the alveolar curve and must not try to put the lateral parts of the cleft forward. Matthews (1955) was also of this opinion. We agree with Matthews that the retropositioning of the premaxilla should be done as a

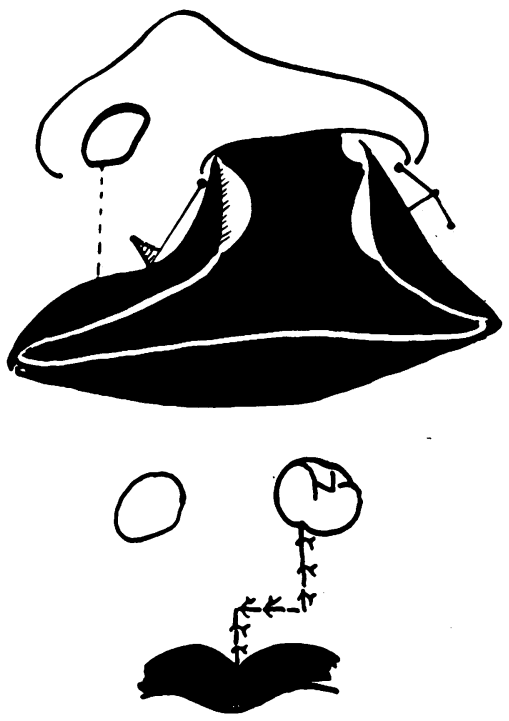

Fig. 2.

single operation, but not in the same session as the plastics of the lip. In many cases the gap between the two alveolar processes is smaller than the premaxilla. Therefore we first have to make an extension of the gap. This is done by means of a plastic plate with a screw (Fig. 6); it is quite easy to put the premaxilla in the alveolar curve after the dilatation (Figs. 7 and 8). Within a very short time the gap is wide enough to start resection of the prevomeric bone, as described by Browne (1932). It is very necessary to prevent the premaxilla from tilting inside; we prefer the teeth to stand out a little. For fixation of the premaxilla we use fragments of bone placed at both sides of the premaxilla in the alveolar curve and fix it with small

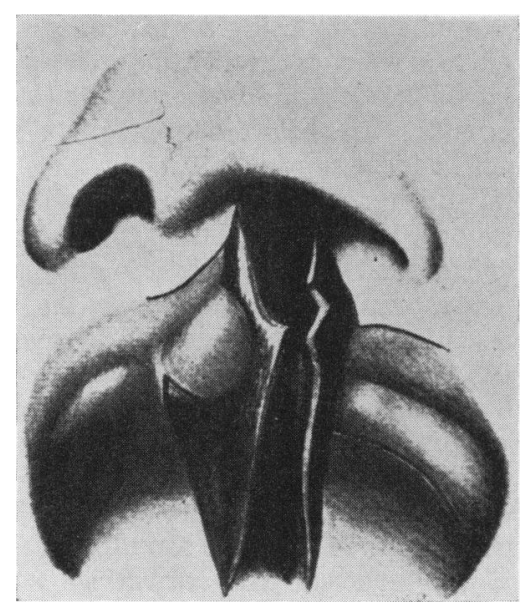

FIG. 3.-From Chirurgische Operationslehre B. Breitner, Vol. I. p. 22.

flaps of mucous nembrane (Fig. 9). We use the bone obtained in the resection of the premaxilla, divided into two pieces. We perforate the premaxilla and fix it with a piece of Kirschner wire in the sagittal direction; then we mobilize the mucous membrane of the alveolar process and the premaxilla, put the fragments of bone in small fissures 


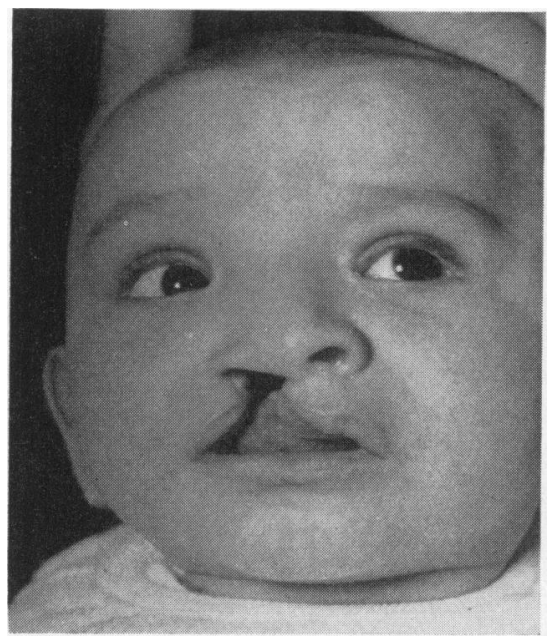

FIG. 4.-Unilateral total hare lip before operation.

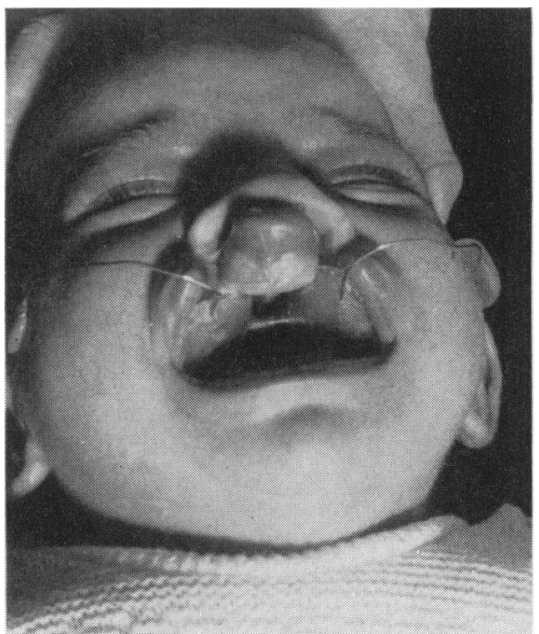

FIG. 6.-Extension of alveolar gap with plastic plate.

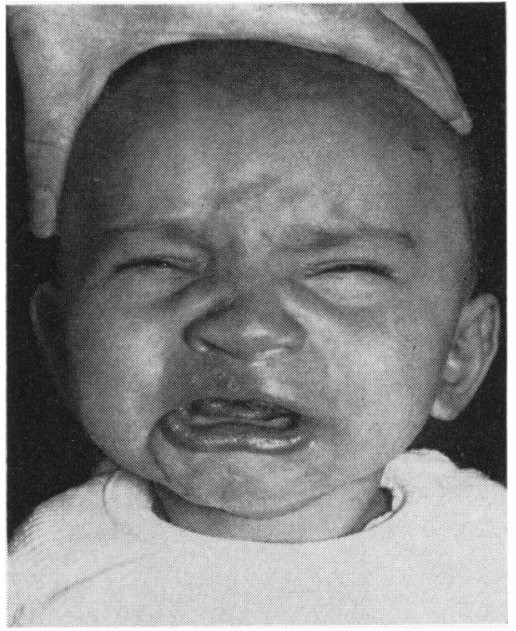

Fig. 5.-Unilateral total hare lip (same case as shown in Fig. 4) after operation.

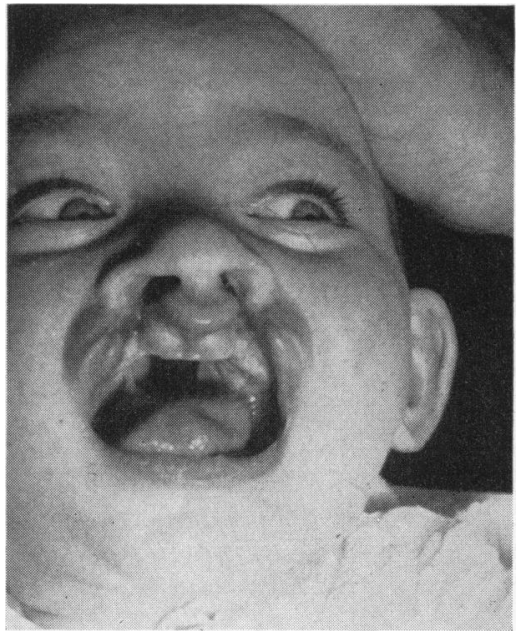

FIG. 7.-Gap between two alveolar processes is wide enough; pre-maxilla is reduced.

FIG. 8.-Plaster casts before and after repositioning of premaxilla. 


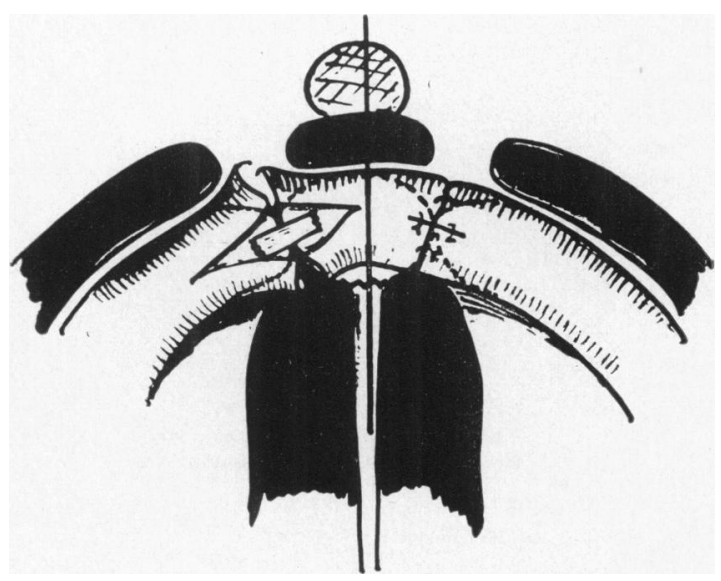

FIG. 9.-Diagram showing effect of resection of prevomeric bone; premaxilla is fixed with a piece of Kirschner wire and with fragments of bone.
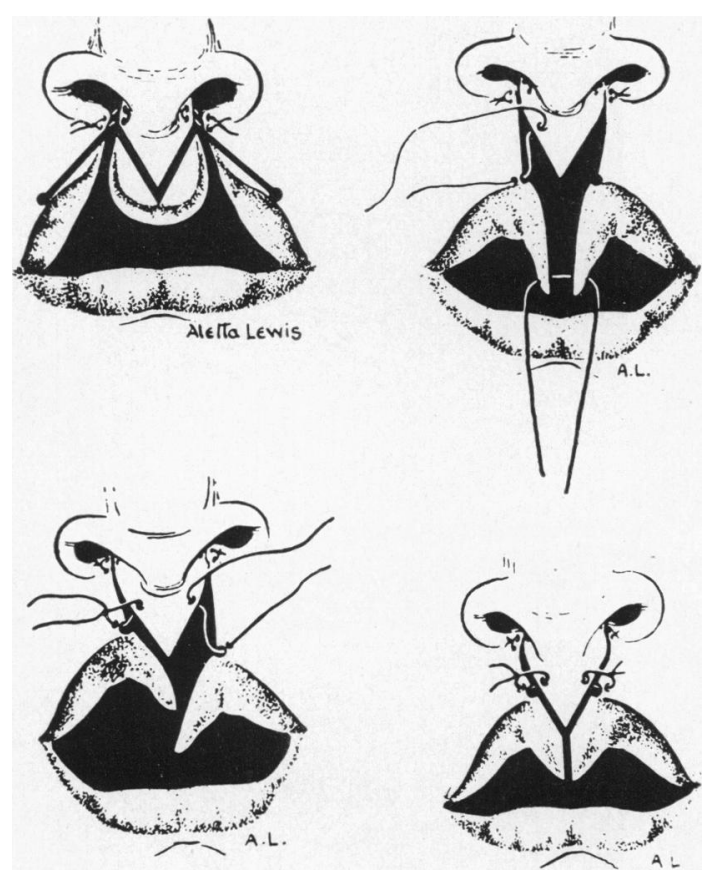

Fig. 10.-Operation for bilateral total hare lip by Denis Browne (Ann. Royal Coll. Surg. Engiand, Vol. 5, Sept. 1949).
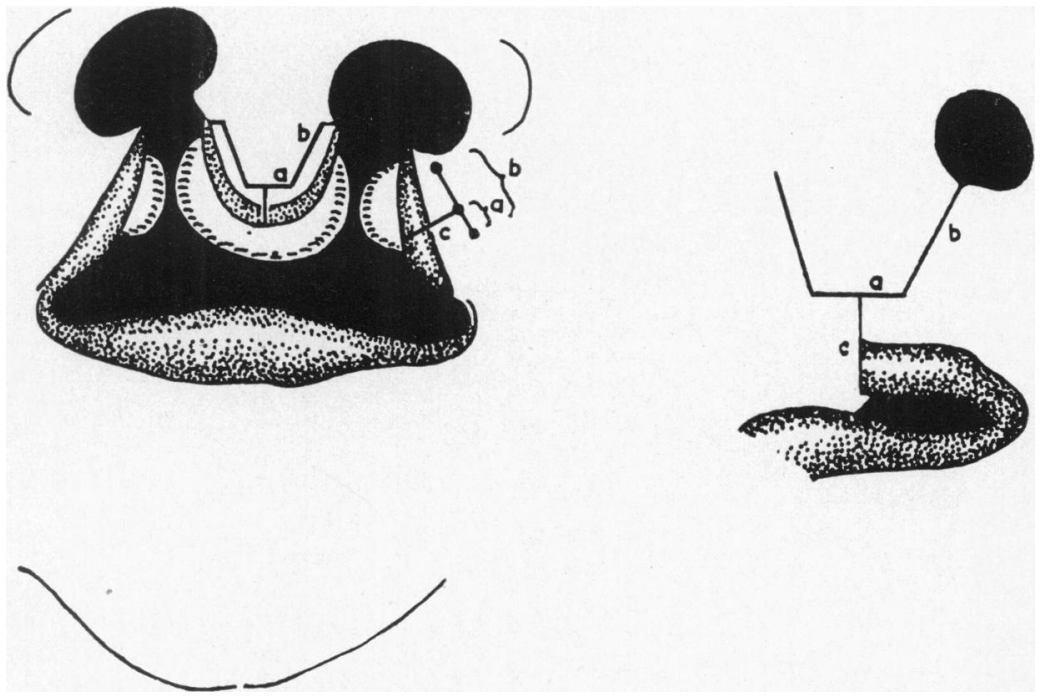

FIG. 11.-Le Mesurier's method at operation for bilateral total hare lip. 

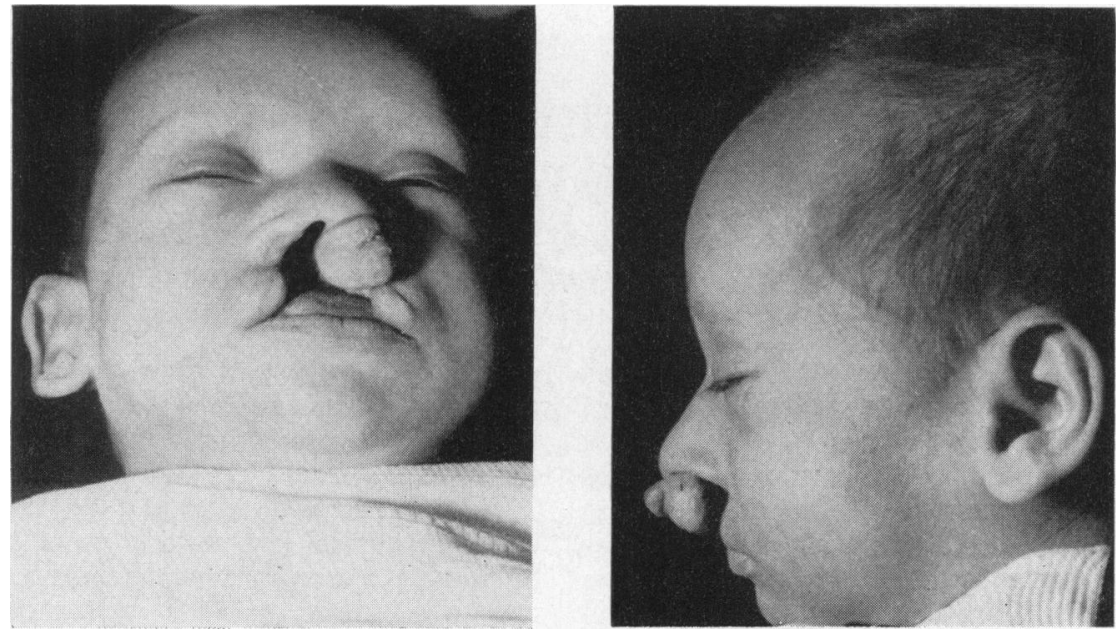

FiG. 12.-Bilateral total hare lip before reposition of premaxilla.

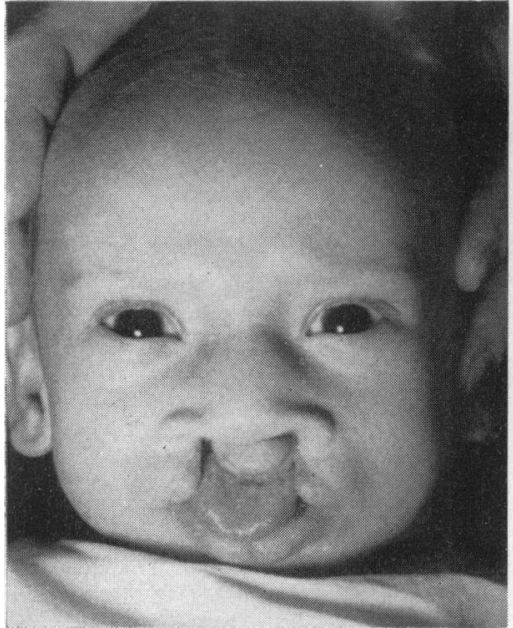

(a)

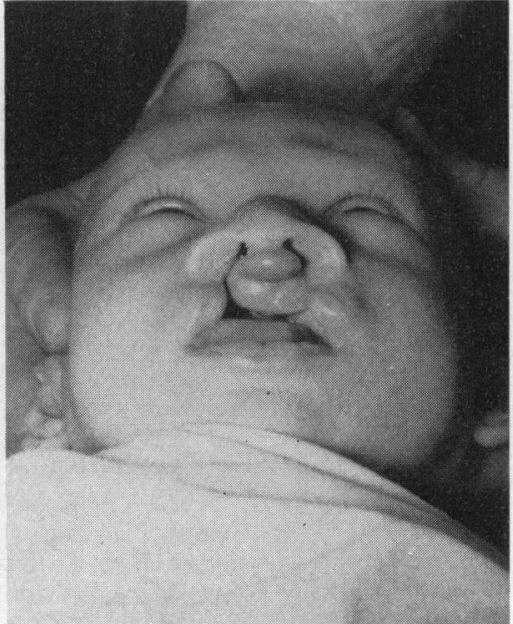

(b)

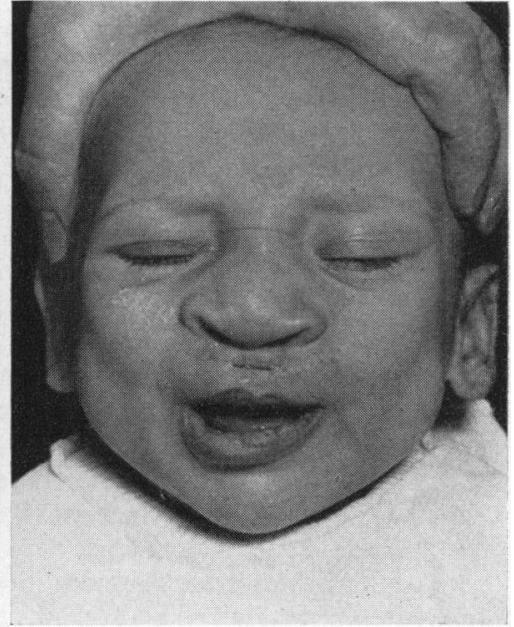

(c)

Fig. 13.-Same case as shown in Fig. 12: (a) and (b) after reposition; (c) after operation.

and make a suture in the mucous membrane. In this way, in the majority of cases it is possible to place the premaxilla in the alveolar curve.

The closure of the hare lip we try to do in one session (Figs. 10 and 11). We use the method of Browne if we have a sufficient amount of material, but if we have only a small middle segment we try separation of the lateral parts of the cleft by the method of le Mesurier.

Figs. 12 and 13 show the result of the operation on a case of bilateral hare lip at the Children's Hospital, Munich.
Axhausen, G. (1936). Technik und Ergebnisse der Gaumenplastik. Thieme, Leipzig.

Browne, Denis (1932). The operation for cleft palate. Brit. J. Surg., $20,7$.

Derichsweiler, Hans (1958). Some observations on the early treatment of hare lip and cleft palate cases. Trans. European ment of hare

Le Mesurier, A. B. (1949). A method of cutting and suturing the lip in the treatment of complete unilateral clefts. Plast. reconstr. Surg., 4, 1.

McNeil, C. Kerr (1956). Congenital oral deformities. Brit. dent. J., $101,191$.

Matthews, D. N. (1955). Der Zwischenkiefer in Fällen von bilateralen Lippen- und Gaumenspalten. Fortschritte der Kiefer- und Gesichts-Chirurgie, ed. K. Schuchardt and M. Wassmund. Gesichts-Chirurgie, ed. K. Sch

vol. I, p. 40. Thieme, Stuttgart.
Schweckendiek, Hermann (1955). Zur zweiphasigen Gaumenspaltenoperation bei primärem Velumverschluss. Ibid., vol. I, p. 73. Thieme, Stuttgart. 